J. Clin. Chem. Clin. Biochem.

Vol. 18, 1980, pp. 23-26

\title{
Effect of Sample Preparation on Cerebrospinal Fluid Protein Patterns in Polyacrylamide Gels
}

\author{
By S. N. Kahn, R. C.Shortman, R. A. Khan and E. J. Thompson \\ Department of Chemical Pathology, Institute of Neurology, The National Hospital, London, U.K.
}

(Received April 10/August 29, 1979)

Summary: The method of preparing CSF and dilute serum samples for polyacrylamide gel electrophoresis has a marked effect on the pattern of the resolved proteins. The incorporation of sucrose or glycerol into the sample seriously impairs the quality of the resolution and affects the actual number of bands resolved and the relative mobility of certain proteins. The use of sucrose as an anti-convection medium in dense samples such as serum and CSF is not recommended.

\section{Effekt der Probenvorbereitung auf das Proteinmuster von Liquor in Polyacrylamidgelen}

Zusammenfassung: Die Methode der Vorbereitung von Liquor und des Verdünnen von Serumproben für die Polyacrylamidgel-Elektrophorese hat einen deutlichen Effekt auf die Auflösung der Proteinmuster. Die Zugabe von Saccharose oder Glycerin zu den Proben verschlechtert regelmäßig die Qualität der Auflösung und beeinflußt die aktuelle Zahl der aufgelösten Probenbanden sowie die relative Beweglichkeit gewisser Proteine. Die Benutzung von Saccharose als konvektions-minderndes Medium in dichten Proben wie Serum und Liquor wird nicht empfohlen.

\section{Introduction}

A recent major treatise on the methodology of polyacrylamide gel electrophoresis devotes four lines to the preparation of the sample for electrophoresis (1). Other workers have described alterations in intensity of bands (2) and in gel electrophoretic patterns (3-5) as a result of incorporating tracking dyes into the system. Changes in the relative amounts of different fractions in cerebrospinal fluid (CSF) concentrated by different methods (6) and in the relative mobilities of individual protein bands in concentrated versus unconcentrăted CSF (13) have also been reported.

Large sections of papers on the methodology of polyacrylamide gel electrophoresis are often devoted to the conditions of polymerization of gels $(1,7)$. Observations in our laboratories, where two workers studying the same samples of CSF consistently obtained differences in protein patterns despite the use of apparently identical electrophoretic methods led us to investigate the effects of differences in the preparation of the sample as well as preparation of the gel on the resulting patterns.

\section{Materials and Methods}

Vertical flat-bed polyacrylamide gel electrophoresis and immunofixation were carried out as previously described (8). Polyacrylamide gel electrophoresis was performed using the same gel and electrode buffers (gel buffer tris- $\mathrm{HCl} 40 \mathrm{mmol} / \mathrm{l}, \mathrm{pH} 8.3$, electrode buffer tris-glycine $40 \mathrm{mmol} / 1, \mathrm{pH} 8.9$ ) in gel rods $12 \mathrm{~cm}$ long and $6 \mathrm{~mm}$ diameter using the method of Davis (9) but omitting the sample and spacer gels, as described by Cumings et al. (10). Polymerization was initiated by adding an equal quantity of ammonium persulphate solution $(6.1 \mathrm{mmol} / \mathrm{l})$ to the acrylamide monomer/gel buffer mixture. Final concentrations in the gel were acrylamide $0.99 \mathrm{~mol} / \mathrm{l}, \mathrm{N}, \mathrm{N}$-methylene bisacrylamide $11.95 \mathrm{mmol} / 1$ and $\mathrm{N}, \mathrm{N}, \mathrm{N}^{\prime}, \mathrm{N}^{\prime}$-tetrame thyl ethylene diamine (TÊMED) $1.93 \mathrm{mmol} / 1$. The monomer/persulphate mixture was overlayered with water before polymerization.

Sets of experiments were carried out to investigate the effects of the following variations in gel preparation:

1. Degassing of solutions was done using either a high-vacuum oil pump or a venturi-ty pe water pump.

2. The order of mixing the gel monomer, gel buffer/TEMED and ammonium persulphate solutions was varied.

Further sets of experiments were performed to investigate the effects of the following sample manipulations:

1. Serum was diluted in $\mathrm{NaCl}, 150 \mathrm{mmol} / \mathrm{l}$ or in $\mathrm{NaCl}, 150$ $\mathrm{mmol} / 1 \mathrm{l}$ containing sucrose, $0.73 \mathrm{~mol} / 1$. 
2. Glycerol or solid sucrose were added to unconcentrated $\mathrm{CSF}$ and diluted serum to final concentrations of $1.37 \mathrm{~mol} / \mathrm{l}$ and $0.73 \mathrm{~mol} / \mathrm{l}$ respectively.

3. Samples containing added glycerol or solid sucrose were either left in flat-bottomed tubes to dissolve slowly or vortexmixed in conical centrifuge tubes for rapid solution.

4. Dense samples were applied to the gels by layering under the upper electrode buffer.

5. Dense or native samples applied directly to the gels were carefully overlayered with upper electrode buffer.

A nominal $100 \mu \mathrm{g}$ of protein was applied to each gel.

\section{Results}

Figure 1 shows the effect of sucrose on the resolution of serum proteins at a 1:50 dilution of serum. A major change in the relative proportions of the two bands with mobilities relative to transferrin $\left(R_{m}\right)$ of 0.13 and 0.19 is evident, with the faster of these bands, more prominent than the slower in the absence of sucrose (1A), becoming much less intense in the presence of sucrose (1B, $1 \mathrm{C})$. There is also overall blurring of the band pattern in the presence of sucrose (1B and $1 \mathrm{C}$ compared with $1 \mathrm{~A}$ ).

Addition of solid sucrose to serum diluted in $\mathrm{NaCl}$, $150 \mathrm{mmol} / 1$, followed by rapid vortex-mixing to hasten solution, results in the appearance of an additional band (arrowed) migrating ahead of transferrin.

Figure 2 shows the effect of vortex-mixing aliquots of CSF for increasing periods in the presence of sucrose. Immunofixation using anti-albumin antiserum shows that the bands, indicated by lines, which appear in the pre transferrin region with prolonged vortex-mixing contain albumin, probably in an aggregated form. The amount of aggregation seems to be related to the duration of vortexing, as shown by the increasing amount of pre trans-

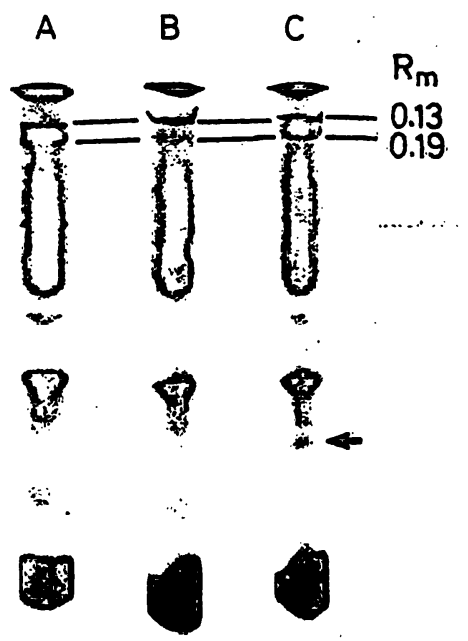

Fig. 1: Serum diluted 1:50. Sample volume $145 \mu$ l. Albumin migration distance $9 \mathrm{~cm} . \mathrm{R}_{\mathrm{m}}=$ mobility relative to transferrin $=1.00$. Lines connect zones of equal relative mobility. Cathode at top.

A. Diluent $\mathrm{NaCl} 150 \mathrm{mmol} / \mathrm{l}$, no sucrose or glycercil added.

B. Diluent $\mathrm{NaCl} 150 \mathrm{mmol} / \mathrm{l}$ containing sucrose, $0.73 \mathrm{~mol} / 1$. No mixing.

C. Diluent $\mathrm{NaCl} 150 \mathrm{mmol} / \mathrm{l}$, sucrose added to $0.73 \mathrm{~mol} / 1$, vortex-mixed.

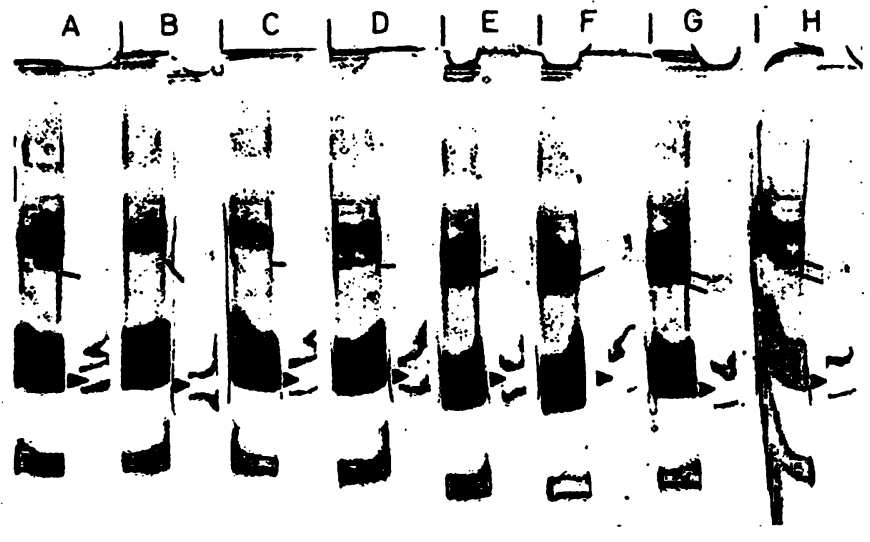

Fig. 2. Slab gel electrophoresis. $50 \mu \mathrm{g}$ of CSF protein in $250 \mu \mathrm{l}$ applied per $8 \mathrm{~mm}$ length of gel upper surface. Cathode at top. All aliquots contain sucrose, $0.73 \mathrm{~mol} / 1$, added as the solid. Each aliquot stained and immunofixed with rabbit anti-human albumin in parallel. Albumin migration distance $6 \mathrm{~cm}$. The major albumin band is severely prozoned (arrowheads). Additional bands reacting with anti-albumin serum are indicated by lines, connecting points of equal electrophoretic mobility in the stained and immunofixed gel slices.
A. No mixing.
B. Vortex-mixing for 5 seconds.
C. Vortex-mixing for 15 seconds.
D. Vortex-mixing for 30 seconds.
E. Vortex-mixing for 60 seconds.
F. Vortex-mixing for 90 seconds.
G. Vortex-mixing for 120 seconds.
H. Vortex-mixing for 180 seconds.

ferrin seen from left to right in the stained gel slices. The single band seen with short vortex-mixing (slices A-E) becomes double with prolonged mixing (slices $\mathrm{F}-\mathrm{H}$ ). The same effect is seen when samples are vortexmixed under nitrogen or mixed by vigorous bubbling of nitrogen through the sample, indicating that oxidation is probably not a major factor in the aggregation.

Figure 3 illustrates the effects of addition of sucrose or glycerol to CSF on the polyacrylamide gel electrophoresis protein pattern. The highest resolution is obtained when native CSF is applied to the gel (3D) - individual bands are sharp and do not exhibit "trailing." The pattern of acidic protein bands (migrating between transferrin and albumin) is clearly resolved, compared with the blurring of this zone and the marked "trailing" especially of albumin in the dense samples $(\mathrm{A}-\mathrm{C})$.

Increased mobility of the pre-albumin band and the slow gamma region is apparent in the presence of sucrose $(3 \mathrm{~B}, 3 \mathrm{C})$.

Vortex-mixing to dissolve solid sucrose results in the appearance of the albumin-containing pre transferrin band '(3B).

Glycerol added to the CSF $\bar{F}$ appears to have less effect on resolution (3A) than sucrose (3B,3C) with less alteration of mobilities especially. 


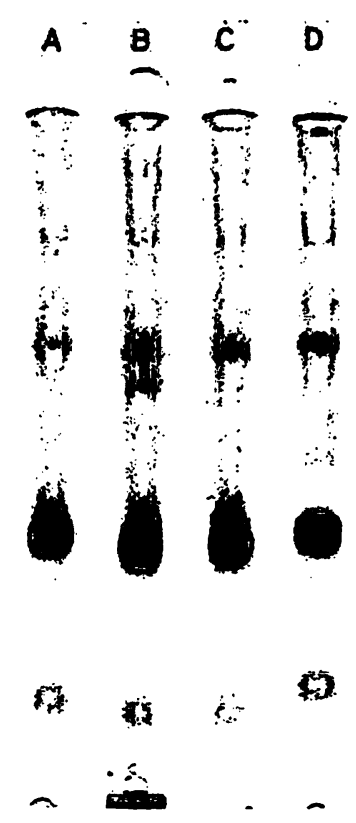

Fig. 3. Unconcentrated CSF. Sample volume $375 \mu l$. Albumin migration distance $9 \mathrm{~cm}$. Cathode at top.

A. Glycerol added to $1.37 \mathrm{~mol} / 1$, not mixed.

B. Sucrose added to $0.73 \mathrm{~mol} / 1$, vortex-mixed.

C. Sucrose added to $0.73 \mathrm{~mol} / \mathrm{l}$, not mixed.

D. No sucrose or glycerol added; native Cr'F.

In the course of this investigation, the following manipulations were found not to affect the final protein patterns in CSF or diluted serum:

1. application of samples under water, under gel buffer or under tank buffer, using the wick system for slab gels described by Ackroyd (11).

2. application of samples to slab gels under tank buffer without the use of a wick (8).

3. electrophoresis in gel rods vs. gel slabs (although minor differences in relative mobilities of some bands were seen).

4. slow $\left(1 \mathrm{~mA} / 26 \mathrm{~mm}^{2}\right.$ of gel surface) vs. fast $(2.5 \mathrm{~mA} /$ $26 \mathrm{~mm}^{2}$ of gel surface) entry of proteins into the gel.

5. bromophenol blue incorporation into sample, upper buffer or both.

6. underlayering of sample under tank buffer vs. overlayering of tank buffer on sample.

7. vigorous (high-vacuum oil pump) vs. mild (water pump) degassing of solutions.

8. varying the order of mixing of water, buffer and acrylamide monomer solutions before degassing and mixing with ammonium persulphate solution.

9. washing of the gel surface with tank buffer vs. water before sample application.

10. addition or chelation of iron (addition of $\mathrm{Fe}^{3+}$ at twice the calculated molar concentration of transferrin and of desferrioxamine at five times the concentration)

11. addition or chelation of calcium (addition of $\mathrm{Ca}^{2+}$ to double the calculated CSF $\mathrm{Ca}^{2+}$ concentration or of disodium EGTA at three times the calculated $\mathrm{Ca}^{2+}$ concentration).
12. vortex-mixing of CSF in the absence of sucrose and glycerol.

\section{Discussion}

The use of sucrose in place of a large-pore gel as an anticonvection medium was first described by Fox et al. (12) and subsequently applied by Cunningham to the analysis of CSF proteins (13). Cunningham originally described changes in the electrophoretic patterns of CSF after concentration but also stated that electrophoresis of human serum in the presence or absence of added sucrose did not reveal any obvious differences. He does not indicate whether the serum was applied neat or diluted since neat serum applied in small $(1-5 \mu \mathrm{l})$ volumes is not subject to the changes described here for diluted samples (T. A. Lubrano \& A. V. Dietz, Hines, Ill. personal communication). Sucrose has been widely used in preparing dilute protein-containing samples for poly acrylamide gel electrophoresis since. To our knowledge, no other study of the effects of sucrose on proteins resolved in polyacrylamide gels has been undertaken.

Polyacrylamide gel electrophoresis of unconcentrated CSF has been in routine use in our laboratory since 1963 and has proved consistently reliable in the same hands for substantiating the clinical diagnosis of multiple sclerosis $(14,15)$. The initial discrepancy in results obtained by the present authors' method, employing slow solution of the sucrose added to the CSF samples, and the results obtained previously, was traced to the earlier practice of vortex-mixing the CSF samples in order to dissolve the solid sucrose added to a final concentration of approximately $0.73 \mathrm{~mol} / \mathrm{l}$.

The tendency of albumin to aggregate into dimers, trimers and even higher polymers during isolation and purification from serum has been well described $(16,17)$. The relatively harsh conditions of vortex-mixing samples in the presence of sucrose or glycerol and the large gasliquid interfaces so formed would also appear to induce albumin aggregation. The presence of these substances appears to be an essential factor for the aggregation process as vortex-mixing of native CSF did not result in albumin aggregation or any other changes in the protein pattern. Nor did aggregation appear to be a result of oxidation since the presence of an atmosphere of nitrogen did not prevent the appearance of the pre transferrin albumin bands. A possible mechanism of protein alteration is a combination of the effects of protein dehydration due to the high sucrose concentration and the presence of a large gas and liquid interface both of which would tend to alter the zeta potential of susceptible proteins.

The presence of sucrose or glycerol in CSF and dilute serum samples not only does not improve but actually impairs electrophoretic resolution. This is clearly illustrated in figure 3 where the best resolved and least 
spread protein bands are obtained from the native CSF sample.

There is no greater technical difficulty nor tendency to mix when running buffer is layered over a native sample than when samples are made dense with sucrose or glycerol. As these substances clearly impair the resolution of the electrophoretic system, we suggest that their use can no longer be justified in polyacrylamide gel electrophoresis of CSF or dilute serum.

\section{Acknowledgements}

We are grateful to Mr. J. Jethwa for technical assistance and to the Department of Medical Illustration at the Institute of Neurology.

S. N. Kahn is supported by the M.R.C.

\section{References}

1. Chrambach, A., Jovin, T. M., Svendsen, P. J. \& Rodbard, D. (1976) in Methods of Protein Separation (Catsimpoolas, N., ed.), Vol. 2, pp. 27-144: Plenum Press, New York.

2. Hattingh, J., Coetzee, N. \& Ross, F. P. (1977). Anal. Bioshem. $80,635-638$.

3. Hiebert, M., Gauldie, J. \& Hillcoat, B. L. (1972). Anal. Biochem. 46, 433-437.

4. Edwards, J. A. \& Muckle, T. J. (1976). Clin. Chim. Acta 67, $35-42$.

5. Muckle, T. J. (1976). Clin. Chim. Acta 73, 57-61.

8. Kahn, S. N. \& Thompson, E. J. (1978). Clin. Chim. Acta 89, 253-265.

9. D̉avis, B. J. (1964). Ann. N.Y. Acad. Sci. 121, 404-427.

10. Cumings, J. N., Shortman, R. C. \& Tooley, M. (1970), Clin. Chim. Acta 27, 29-34.

11. Ackroyd, P. (1967). Anal. Biochem. 19, 399-410.

12. Fox, D. J., Thurman, D. A. \& Boulter, D. (1963). Biochem. J. $87,29 \mathrm{P}-30 \mathrm{P}$.

13. Cunningham, V. R. (1964), J. Clin. Pathol. 17, 143-148.

14. Thompson, E. J. (1977). Brit. Med. Bull. 33, 28-33.

6. Krause, H. D., Wisser, H. \& Pirke, K. M. (1975). Z. Klin. Chem. Klin. Biochem. 13, 79-84.

7. Rodbard, D. \& Chrambach, A. (1971). Anal. Biochem. 40, 95-134.

\& McDonald, W. I. (1979). Brit. Med. J.I, 16-17.

16. Solli, N. J. \& Bertolini, M. J. (1977). Vox Sang. 32, 239-241. 17. Skoog, B. \& Granstrand, B. (1977). Vox Sang. 32, 242-246.

Dr. Sidney N. Kahn, Neuroimmunology Laboratory, Department of Neurochemistry, Institute of Neurology, The National Hospital, Queen Square, London WC1N 3BG, United Kingdom 